\title{
LETTERS
}

\section{Inhaled all-trans retinoic acid in an individual with severe emphysema}

\section{To the Editors:}

A patient with extensive emphysema was treated with liposomal all-trans retinoic acid (ATRA) using a controlled inhalation manoeuvre. After a gradual increase from $0.1 \mathrm{mg}$ to $3 \mathrm{mg}$ ATRA per day, the patient was treated at a level of $1 \mathrm{mg} \cdot$ day $^{-1}$ for 4 days per week. Over the 6-month observation period there was an improvement of forced expiratory volume in $1 \mathrm{~s}$ (FEV1) from $16 \%$ to $21 \%$ predicted and an increase from $400 \mathrm{~m}$ to $615 \mathrm{~m}$ in the 6-min walking test (6MWT), although there was no apparent change in lung morphology with highresolution computed tomography (HRCT). Biochemical analysis demonstrated a decrease in exhaled isoprostane and a decrease in serum interleukin (IL)-13. In addition, desmosine excretion decreased from $115 \mu \mathrm{g} \cdot \mathrm{g}^{-1}$ creatinine to $<35 \mu \mathrm{g} \cdot \mathrm{g}^{-1}$ creatinine (normal range $25 \pm 4 \mu \mathrm{g} \cdot \mathrm{g}^{-1}$ ). The data suggest that inhaled ATRA reduces inflammation and lung destruction processes and may be of benefit in selected cases of emphysema.

The patient was a 45-yr-old male never-smoker of Caucasian origin with no family history of lung disease. He had worked in the wood industry and then as an electrician without any known asbestos exposure for 7 yrs until diagnosis. He first developed dyspnoea in 2002 and HRCT analysis revealed extensive basal centrilobular emphysema. Standard inhalation therapy was Spiriva ${ }^{\circledR}$ (tiotropium $18 \mu \mathrm{g}$ q.d.; Boehringer Ingelheim Pharma, Ingelheim, Germany) and Symbicort ${ }_{\circledR}$ (budesonid $160 \mu \mathrm{g}$ plus formoterol $4.5 \mu \mathrm{g}$ b.i.d.; AstraZeneca, London, UK). The patient was admitted to hospital several times with Haemophilus influenzae airway infection and, as of summer 2007, he was on long-term oxygen therapy at 2$3 \mathrm{~L} \cdot \mathrm{min}^{-1}$ for $24 \mathrm{~h}$ per day. The $\alpha_{1}$-antitrypsin level was normal at $171 \mathrm{mg} \cdot \mathrm{dL}^{-1}$ and sequencing of the SERPINA1 (AAT) gene (exons plus flanking sequence) showed the patient to be homozygous for the common M1V variant with no other sequence variation.

Retinoic acid (RA) acts via an retinoid $X$ receptor-RA receptor- $\alpha$ nuclear receptor complex. RA has been demonstrated to promote alveolarisation in a rat model [1], but other reports in rats and mice failed to demonstrate such an effect [25]. Furthermore, ATRA can improve the protease/anti-protease balance [6, 7] and has anti-inflammatory activity [8]. Oral therapy with ATRA in chronic obstructive pulmonary disease (COPD) has been reported and there is evidence of some improvement $[9,10]$. We reasoned that topical application to the lung might be superior to systemic oral therapy.

Therefore, the patient was considered for compassionate use of liposomal ATRA applied by controlled inhalation. For this di-oleoyl-phosphatidyl serine (OOPS) and 1-palmitoyl-2-oleyl-phosphatidyl choline (POPC) (Mandapro AG, Ettingen, Switzerland) were dissolved at an OOPS/POPC ratio of 0.43 in chloroform [6]. ATRA (\#700121-0005; Fagron, Barsbüttel, Germany) was dissolved in $96 \%$ ethanol at $2 \mathrm{mg}$ ATRA $\mathrm{mL}^{-1}$. On a weekly basis, $175 \mathrm{mg}$ of lipids was admixed with $7 \mathrm{mg}$ of ATRA, and liposomes were generated and extruded to $\leqslant 0.4 \mu \mathrm{m}$ by passage through polycarbonate filters (Nuclepore \#110607; Costar, Bodenheim, Germany) in an extruder device (B002; Lipex Biomembranes, Vancouver, BC, Canada). Resultant unilamellar liposomes were passed through a $0.2-\mu \mathrm{m}$ filter and stored at $4^{\circ} \mathrm{C}$ for use within 2 weeks.

After having given informed consent, the patient inhaled ATRA in 1- to 3-mL volumes of liposomal preparations. Inhalation was controlled using the AKITA $^{2}$ APIXNEB $_{\mathbb{R}}$ device (Activaero, Gemünden/Wohra, Germany) with $500 \mathrm{~mL}$ of the liposomal ATRA aerosol followed by $100 \mathrm{~mL}$ of air only. The drug was administered three times a week (Tuesday, Wednesday, Thursday) starting with a dose of $0.1 \mathrm{mg}$, with a weekly increase to $0.3 \mathrm{mg}, 1 \mathrm{mg}$ and finally $3 \mathrm{mg}$ of ATRA.

There were no side-effects reported by the patient, and physical and laboratory examination did not show any evidence of adverse effects. After 4 weeks of incremental therapy the patient was continued on ATRA at $1 \mathrm{mg}, 4$ days a week (Tuesday, Wednesday, Thursday, Friday) for 5 months. From then on, the patient was continued on ATRA therapy without further followup and the restrictions on additional therapies and supportive measures (e.g. exercise training) were lifted. This report covers 6 months of controlled ATRA therapy.

After several weeks of therapy, the patient noted an improved performance in daily life and he was able to spend several hours without oxygen supplementation on weekends. Analysis of lung function before therapy and at the end of the study period showed an improvement in FEV1 and blood gases. In addition, there was a strong increase in the standard 6MWT (table 1).

Although better supportive care during the study period may have added to the clinical improvement, we found clear biochemical changes that support a specific action of liposomal ATRA. This includes a decrease in plasma IL-13, neutrophil elastase in sputum and desmosine in urine (table 1). In addition, sputum eosinophils were increased to $12 \%$ before ATRA treatment without any evidence of asthma in lung function testing (table 1). Eosinophils decreased to $6 \%$, a phenomenon that may be due to an ATRA-induced shift to neutrophils [11]. 8-isoprostane levels determined in exhaled breath condensate showed a substantial decrease from $14.6 \mathrm{pg} \cdot \mathrm{mL}^{-1}$ before the study to $4.3 \mathrm{pg} \cdot \mathrm{mL}^{-1}$ at the end of 


\begin{tabular}{|c|c|c|}
\hline Parameter & $\begin{array}{c}\text { Before ATRA } \\
\text { therapy }\end{array}$ & $\begin{array}{l}6 \text { months after } \\
\text { ATRA therapy }\end{array}$ \\
\hline TLC & 8.5 & 8.7 \\
\hline VCmax & 2.1 & 1.9 \\
\hline FEV1 L without dilation & 0.74 & 0.94 \\
\hline FEV1 L post-dilation & 0.83 & ND \\
\hline FEV1 \% pred without dilation & 16 & 21 \\
\hline FEV1 \% pred post-dilation & 18 & ND \\
\hline ITGV & 7.2 & 7.5 \\
\hline Resistance $\mathbf{k P a} \times \mathbf{s} \cdot \mathrm{L}^{-1}$ & 0.99 & 0.66 \\
\hline $\mathrm{O}_{2} \mathrm{mmHg}$ at $3 \mathrm{~L} \mathrm{O}_{2}$ & 68 & 81 \\
\hline $\mathrm{CO}_{2} \mathrm{mmHg}$ & 59 & 47 \\
\hline 6-min walking test $\mathrm{m}$ & 400 & 615 \\
\hline C-reactive protein in plasma $\mathrm{mg} \cdot \mathrm{L}^{-1}$ & 17.8 & 3.7 \\
\hline $\mathrm{IL}-13$ in plasma $\mathrm{pg} \cdot \mathrm{mL}^{-1}$ & 21.8 & 2.2 \\
\hline TNF in plasma $\mathrm{pg} \cdot \mathrm{mL}^{-1}$ & 4.1 & 1.9 \\
\hline Sputum eosinophils \% & 12 & 6 \\
\hline Sputum neutrophils \% & 65 & 64 \\
\hline 8-isoprostane in EBC $\mathrm{pg} \cdot \mathrm{mL}^{-1}$ & 14.6 & 4.3 \\
\hline Sputum neutrophil elastase $\mathrm{ng} \cdot \mathrm{mL}^{-1}$ & 7.4 & 2.2 \\
\hline Desmosine in urine $\mu \mathrm{g} \cdot \mathrm{g}^{-1}$ creatinine & 114.8 & 35.3 \\
\hline
\end{tabular}

ATRA: all-trans retinoic acid; TLC: total lung capacity; VCmax: maximum vital capacity; FEV1: forced expiratory volume in $1 \mathrm{~s}$; \% pred: \% predicted; ITGV: intrathoracic gas volume; IL: interleukin; TNF: tumour necrosis factor; EBC: exhaled breath condensate; ND: not done.

the study. Also, IL-13 in plasma, as detected by multiplex ELISA, was high before therapy and decreased over time (table 1). There was no clear pattern in the matrix metalloproteinase-9/tissue inhibitor of metalloproteinase-1 ratio in patient plasma and sputum (data not shown).

Elastin degradation by proteases is an important element of lung destruction in emphysema and this can be monitored via the levels of the amino acid desmosine, which is released upon digestion and excreted in urine. Desmosine was measured via capillary electrophoresis [12]. The levels of this degradation product showed a gradual decrease and were near the normal range at 6 months (table 1).

Regarding the mechanisms of action of liposomal ATRA, we did not have tools with the appropriate sensitivity to demonstrate an increase in alveoli in this clinical setting. However, we found clear evidence for an anti-inflammatory action of liposomal ATRA, with a decrease of 8-isoprostane in exhaled breath condensate and a decrease of the IL-13 plasma levels. There is conflicting evidence of the role of IL-13 in typical COPD patients $[13,14]$, but in the present case IL-13 was substantially increased and responded to liposomal ATRA. When looking at sputum fluid there was a decrease in neutrophil elastase. This decrease may explain, in part, a reduced degradation of elastin as evidenced by a decrease in the desmosine excretion. The latter end-point is obviously crucial to the course of the disease since it indicates a blockade of further lung destruction.
M. Frankenberger*, I. Heimbeck*, W. Möller*, S. Mamidi*, G. Kaßner*, K. Pukelsheim", M. Wjst", M. Neiswirth*, P. Kroneberg ', D. Lomas ${ }^{+}$, D. Halsall ${ }^{\S}$, P. Iadarola ${ }^{f}$, A. Fertl ${ }^{*}$, K. Häußinger* and L. Ziegler-Heitbrock*

*Clinical Cooperation Group Inflammatory Lung Diseases, Helmholtz Zentrum München and Asklepios Fachklinik Gauting, Gauting, and "Helmholtz Zentrum München, Institute for Lung Biology and Disease, Neuherberg, and `Activaero GmbH, Gemünden/Wohra, Germany. ${ }^{+}$Dept of Medicine, University of Cambridge, Cambridge Institute for Medical Research, and ${ }^{\S}$ Dept Clinical Biochemistry, Addenbrooke's Hospital, Cambridge, UK. ${ }^{f}$ Dept of Biochemistry, University of Pavia, Pavia, Italy.

Correspondence: L. Ziegler-Heitbrock, Clinical Cooperation Group Inflammatory Lung Diseases, Helmholtz Zentrum München and Asklepios Fachklinik Gauting, Robert-Koch Allee 29, D-82131 Gauting, Germany. E-mail: zieglerheitbrock@helmholtz-muenchen.de

Statement of Interest: Statements of interest for M.

Frankenberger, D. Lomas and L. Ziegler-Heitbrock can be found at www.erj.ersjournals.com/misc/statements.dtl

Acknowledgements: We would like to thank P. Fankhauser (Mandapro, Ettingen, Switzerland) for generous provision of lipids.

\section{REFERENCES}

1 Massaro GD, Massaro D. Retinoic acid treatment abrogates elastase-induced pulmonary emphysema in rats. Nat Med 1997; 3: 675-677.

2 Fujita $\mathrm{M}$, Ye $\mathrm{Q}$, Ouchi $\mathrm{H}$, et al. Retinoic acid fails to reverse emphysema in adult mouse models. Thorax 2004; 59: 224-230.

3 Lucey EC, Goldstein RH, Breuer R, et al. Retinoic acid does not affect alveolar septation in adult FVB mice with elastase-induced emphysema. Respiration 2003; 70: 200-205.

4 March TH, Bowen LE, Finch GL, et al. Effects of strain and treatment with inhaled aII-trans-retinoic acid on cigarette smokeinduced pulmonary emphysema in mice. COPD 2005; 2: 289-302.

5 March TH, Cossey PY, Esparza DC, et al. Inhalation administration of all-trans-retinoic acid for treatment of elastase-induced pulmonary emphysema in Fischer 344 rats. Exp Lung Res 2004; 30: 383-404.

6 Frankenberger M, Hauck RW, Frankenberger B, et al. All transretinoic acid selectively down-regulates matrix metalloproteinase-9 (MMP-9) and up-regulates tissue inhibitor of metalloproteinase-1 (TIMP-1) in human bronchoalveolar lavage cells. Mol Med 2001; 7: 263-270.

7 Jalian HR, Liu PT, Kanchanapoomi M, et al. All-trans retinoic acid shifts propionibacterium acnes-induced matrix degradation expression profile toward matrix preservation in human monocytes. J Invest Dermatol 2008; 128: 2777-2782.

8 Weber C, Calzada-Wack JC, Goretzki M, et al. Retinoic acid inhibits basal and interferon-gamma-induced expression of intercellular adhesion molecule 1 in monocytic cells. J Leukoc Biol 1995; 57: 401-406.

9 Mao JT, Goldin JG, Dermand J, et al. A pilot study of all-transretinoic acid for the treatment of human emphysema. Am J Respir Crit Care Med 2002; 165: 718-723. 
10 Roth MD, Connett JE, D'Armiento JM, et al. Feasibility of retinoids for the treatment of emphysema study. Chest 2006; 130: 1334-1345.

11 Paul CC, Mahrer S, Tolbert M, et al. Changing the differentiation program of hematopoietic cells: retinoic acid-induced shift of eosinophil-committed cells to neutrophils. Blood 1995; 86: 3737-3744.

12 Viglio S, Annovazzi L, Luisetti M, et al. Progress in the methodological strategies for the detection in real samples of desmosine and isodesmosine, two biological markers of elastin degradation. J Sep Sci 2007; 30: 202-213.
13 Kim EY, Battaile JT, Patel AC, et al. Persistent activation of an innate immune response translates respiratory viral infection into chronic lung disease. Nat Med 2008; 14: 633-640.

14 Saha S, Mistry V, Siva R, et al. Induced sputum and bronchial mucosal expression of interleukin-13 is not increased in chronic obstructive pulmonary disease. Allergy 2008; 63: 1239-1243.

DOI: $10.1183 / 09031936.00105309$

\section{Diffuse idiopathic pulmonary neuroendocrine hyperplasia, chronic eosinophilic pneumonia, and asthma}

\section{To the Editors:}

Herein we report the progression of irreversible airflow obstruction in a patient with diffuse idiopathic pulmonary neuroendocrine cell hyperplasia (DIPNECH). Following an episode of chronic eosinophilic pneumonia associated with raised sputum substance $\mathrm{P}$ and infiltration of the interstitum and alveolar spaces with eosinophils, the fixed airflow limitation became variable (i.e. asthma), requiring treatment with inhaled corticosteroids and long-acting $\beta$-agonists.

A number of airway diseases, such as smoker's bronchitis, emphysema, asthma, bronchiolitis and bronchiectasis, can lead to chronic airflow limitation [1]. However, variability and reversibility of airflow limitation is only observed in asthma. Inflammatory cell infiltration of the airway, particularly with eosinophils, may be one of the mechanisms of variable airflow limitation [2]. Although the natural history of eosinophilic bronchitis is not well known, it is believed that it may lead to chronic irreversible airflow limitation [3]. However, it is unusual for chronic irreversible airflow limitation to show variability and improvement in airway calibre following treatment with corticosteroids. This case report describes the changes in lung function and response to treatment of a patient with chronic airflow limitation due to smoker's bronchitis and DIPNECH following eosinophilic inflammation of the airway and the interstitium. The case also highlights the importance of measuring airway inflammation in the management of airway diseases.

A 65-yr-old female with a history of hypercholesterolemia, vertebral osteoarthritis, gall stone disease and endometriosis but no previous respiratory illness, except a mild intermittent cough for the past 4 yrs, presented with fever, night sweats, worsening cough and weight loss of $6.8 \mathrm{~kg}$ (15 lbs). She did not have muscle or joint aches, a skin rash or bowel symptoms. She appeared pale and had inspiratory crackles in her left axillary region. After accumulating a 12 pack-yr smoking history, she had quit smoking $15 \mathrm{yrs}$ earlier. She had immigrated to Canada from Germany in 1961. She did not keep any pets at home, had not recently travelled outside of Ontario (Canada) and did not have any known risk factors for HIV infection. She was not on any medications that could cause adverse effects on the lung.

A blood count showed anaemia, lymphopenia, mild eosinophilia $\left(1.0 \times 10^{9} \cdot \mathrm{L}^{-1}\right)$ and thrombocytosis. An auto-antibody profile and fungal and avian precipitins were negative. Skin prick tests with common aeroallergens including aspergillus were also negative. A tuberculin test showed a 20-mm induration. A chest radiograph performed at the onset of her illness showed soft fluffy infiltrates of both upper zones which became extensive 1 week later. At the time of assessment in our clinic (Firestone Institute for Respiratory Health, Hamilton, Ontario), a chest radiograph showed almost complete resolution of the right upper-zone infiltrate and further extension of the infiltrate in the left lung to the mid-zones. A highresolution computed tomography (HRCT) scan of the chest showed ground-glass opacities in both upper lobes and extensive infiltrates with air bronchogram in the left lower lobe extending to the periphery of the lung. Sputum and bronchoalveolar lavage fluid examination did not grow any pathogenic organisms. Substance $\mathrm{P}$ in sputum supernatant (measured by radioimmunoassay using antisubstance $\mathrm{P}$ antibody (Peninsula Laboratories, San Carlos, CA, USA), as previously described [4]) was elevated at $1,210 \mathrm{pg} \cdot \mathrm{mL}^{-1}$ (normal $<400 \mathrm{pg} \cdot \mathrm{mL}^{-1}$ ). Spirometry showed a mixed obstructive and nonobstructive ventilatory pattern without variable airflow obstruction (table 1).

Histopathological examination of a video-assisted thorascopic biopsy from the left lower lobe showed two distinct disease processes. The alveoli were filled with abundant eosinophils and some fibrinous exudate, which extended into the related respiratory bronchioles and showed evidence of organisation. The muscular pulmonary arteries and the veins of the affected areas showed low-grade non-necrotising vasculitis and scant infiltration by eosinophils and lymphocytes. Examination for fungi by Grocott staining was negative. These findings were consistent with chronic eosinophilic pneumonia (fig. 1a). The other finding was proliferation of neuroendocrine cells, which stained positive for chromogranin $\mathrm{A}$ and stomatophysin in 